\title{
Total Synthesis of (-)-Minovine
}<smiles>C=C(CC)CCC(=O)N(CCc1cn(C)c2ccccc12)c1nnc(C(C)=O)o1</smiles>

A<smiles>CCC12OC3(CN=NN3)[C@@]1(CC)CCC(=O)N2CCc1c[nH]c2ccccc12</smiles>

B

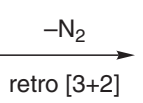<smiles>CCC1(CC)CCC(=O)N(CCc2c[nH]c3ccccc23)C1=O</smiles>

[3+2]

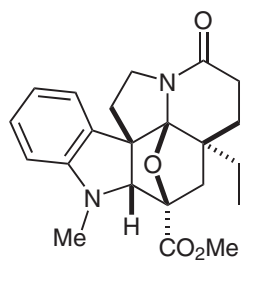

$\mathrm{D}$
Significance: Three rings in the target molecule together with five stereogenic centers were created in a single operation by heating the 1,3,4-oxadiazole A in 1,2-dichlorobenzene. Three tandem pericyclic processes were involved: a Diels-Alder reaction to form $\mathbf{B}$, a retro [3+2] reaction to form dipole $\mathbf{C}$, and a dipolar cycloaddition to form $\mathbf{D}$ in $74 \%$ yield.
Comment: Natural Minovine was reported to have an $[\alpha]_{D}=0$. Minovine prepared from enantiopure (+)-D (chromatographic resolution) displayed remarkable solvent-dependent but concentrationindependent optical rotations accounting for the observed rotation. These studies established that natural Minovine is a single enantiomer which does not racemize on heating. 